\title{
Temporal preparation improves temporal resolution: Evidence from constant foreperiods
}

\author{
KaRin M. Bausenhart, BetTina Rolke, and Rolf UlRich \\ University of Tübingen, Tübingen, Germany
}

\begin{abstract}
Recent research shows that temporal preparation within a constant foreperiod design improves the spatial resolution of visual perception. The present experiments were designed to investigate whether similar benefits of temporal preparation can be observed in a task that requires high temporal resolution. In three experiments, we assessed the effect of temporal preparation on temporal order judgments (TOJs). In Experiment 1, short foreperiods facilitated TOJ for two spatially adjacent dots. This finding was replicated in Experiment 2, in which the temporal order of two spatially overlapping stimuli ("+" and " $x$ ") had to be discriminated. Experiment 3 investigated the time course of temporal preparation by extending these findings to a wide range of different foreperiod durations. The present findings corroborate recent evidence for a perceptual locus of temporal preparation. Most importantly, they show that temporal preparation within a constant foreperiod design improves the temporal resolution of visual perception, independently of whether TOJ requires a decision about the location or about the identity of the target stimuli.
\end{abstract}

Starting with the work of Woodrow (1914), the ability to prepare temporally for upcoming events has been acknowledged as an important determinant for human performance. Traditionally, research on temporal preparation ${ }^{1}$ has employed the so-called foreperiod paradigm (for an overview, see Niemi \& Näätänen, 1981). In this paradigm, a warning signal precedes a target stimulus by a certain amount of time (i.e., the foreperiod). The length of the foreperiod and the distribution of the foreperiods across trials influence the preparatory processes differentially. For example, foreperiod duration can be kept constant within a block of trials and be varied only across blocks of trials. In this constant foreperiod paradigm, reaction time (RT) increases (except for very short foreperiods) with increasing foreperiod duration (e.g., Klemmer, 1956; Müller-Gethmann, Ulrich, \& Rinkenauer, 2003). In contrast, when foreperiod duration is varied within blocks of trials (variable foreperiod paradigm), this pattern of results is reversed: RT decreases with increasing foreperiod duration (e.g., Drazin, 1961; Klemmer, 1956).

It has been assumed that these results are due to two different sources of uncertainty (see, e.g., Klemmer, 1956; Niemi \& Näätänen, 1981). First, constant foreperiods enable participants to learn the foreperiod duration of the current block. Accordingly, participants can estimate the duration of this foreperiod, and thus prepare for the expected moment of target presentation. Importantly, it is well known that short durations can be estimated more accurately than long durations (Näätänen, Muranen, \& Merisalo, 1974). Due to this time uncertainty (Klemmer, 1956), preparatory activity can be timed more precisely on the moment of target presentation after short than after long foreperiods, thus yielding a shorter RT for short than for long foreperiods.

In the variable foreperiod paradigm, however, a second source of uncertainty contributes to the foreperiod effect: expectancy of the target stimulus. Since foreperiod duration varies randomly from trial to trial, at the beginning of each trial, targets might be presented after every possible foreperiod duration with equal probability. Consequently, during the time course of a single trial, the conditional probability of target delivery increases. For example, if the target has not been presented after the shortest foreperiod, the probability rises that it will be presented after one of the longer foreperiod durations. It has been suggested that participants utilize this increase to build up expectancies about the upcoming foreperiod duration, and prepare more for the moments with a higher probability of target presentation. Accordingly, in the variable foreperiod design, participants are better prepared for target presentation if foreperiod is long rather than short, and thus, RT decreases with increasing foreperiod duration. Evidence for this notion stems from studies that employ so-called nonaging foreperiod distributions, in which the frequency of short foreperiods is increased in such a way that the conditional probability for target presentation remains rather constant throughout the trial. It has been repeatedly shown that the variable foreperiod effect can be strongly reduced or even eliminated by such foreperiod distributions (e.g., Näätänen, 1970, 1971; Nickerson \& Burnham, 1969). ${ }^{2}$

Whereas these accounts can explain quite well the quantitative pattern of results, the nature of the prepara-

K. M. Bausenhart, karin.bausenhart@uni-tuebingen.de 
tion process itself remains rather unclear. However, much empirical research has already been conducted to investigate which stages of information processing are influenced by temporal preparation. For example, research employing foreperiod designs demonstrated a variety of motor-related variables that are affected by temporal preparation-for example, RT (e.g., Karlin, 1959; Klemmer, 1956; A. F. Sanders, 1980; see also Niemi \& Näätänen, 1981), response force (e.g., Mattes \& Ulrich, 1997), reflex amplitudes (Brunia, Scheirs, \& Haagh, 1982; Requin, Bonnet, \& Semjen, 1977), motor-evoked potentials (Hasbroucq, Kaneko, Akamatsu, \& Possamaï, 1997), and the contingent negative variation (Gaillard \& Näätänen, 1973; Loveless \& Sanford, 1974; Trillenberg, Verleger, Wascher, Wauschkuhn, \& Wessel, 2000). More recent work in the field of temporal preparation addressed the question of whether, in addition to motor-related behavior, premotor processing might be enhanced by preparation. Studies employing the psychological refractory period (Bausenhart, Rolke, Hackley, \& Ulrich, 2006) or psychophysiological measures (Hackley, Schankin, Wohlschlaeger, \& Wascher, 2007; Hackley \& Valle-Inclán, 2003; Müller-Gethmann et al., 2003) have provided evidence for this notion. These results are further supported by studies demonstrating that temporal preparation facilitates perceptual processing of visual (Rolke, in press; Rolke \& Hofmann, 2007) as well as auditory (Bausenhart, Rolke, \& Ulrich, 2007) stimuli. For example, Rolke and Hofmann employed a masking procedure to investigate the effects of temporal preparation on performance in a perceptual discrimination task.
They found improved accuracy of spatial gap discrimination for short in comparison with long constant foreperiods. This result strongly suggests that temporal preparation improves spatial resolution in visual perception, and thus influences perceptual processing.

On the basis of the results described above, one might ask whether this facilitating influence of temporal preparation is restricted to the processing of spatial stimulus properties, or whether other aspects of perception also benefit from temporal preparation. This question seems especially interesting in light of studies that have demonstrated that attentional influences on perception are not necessarily beneficial. For example, it has been shown that spatial attention enhances spatial resolution, but can impair processing of temporal stimulus properties (e.g., Hein, Rolke, \& Ulrich, 2006; Yeshurun \& Levy, 2003). Therefore, in the present study, we addressed the question of whether temporal preparation within a constant foreperiod paradigm enhances the processing of temporal stimulus properties. Specifically, we investigated whether temporal preparation enhances discrimination performance in a temporal order judgment (TOJ) task. In this task, participants have to judge the temporal order of two target stimuli, which are presented with a varying stimulus onset asynchrony (SOA). For example, in our Experiment 1, two dots were presented, and participants had to indicate which of the two dots (the one presented to the left or the one presented to the right of a fixation cross) was presented first.

Performance in TOJ can be described by two parameters (Figure 1): (A) the point of subjective simultaneity (PSS),

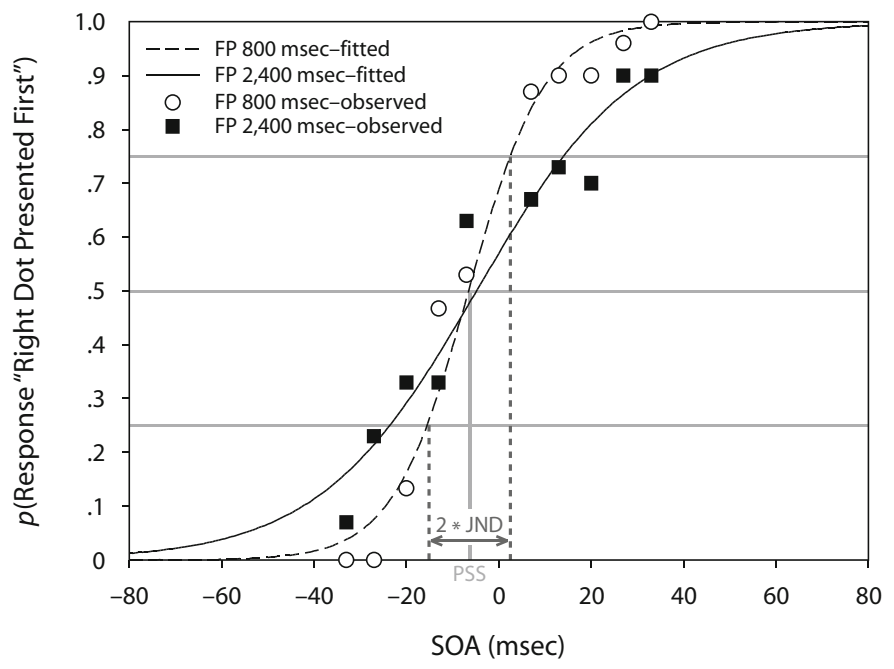

Figure 1. Observed probability for a "right dot presented first" response at different stimulus onset asynchronies (SOAs) and the corresponding fitted psychometric functions for two foreperiod durations. Negative SOAs indicate that the left dot was presented first; positive SOAs indicate that the right dot was presented first. From the psychometric functions, the point of subjective simultaneity (PSS) can be derived as the SOA duration that corresponds to $\mathbf{5 0 \%}$ "right dot first" responses. The just noticeable difference (JND) reflects the minimum SOA duration needed to judge the temporal order of the stimuli correctly (half the interquartile range of the psychometric function). For clarity, PSS and JND are depicted only for the 800-msec foreperiod (FP) condition. The data shown in this figure are the results of 1 participant in Experiment 1. 
which may indicate a bias in temporal stimulus processing, and (B) the just noticeable difference (JND) as an index of the accuracy of temporal processing, and thus, temporal resolution (e.g., Sternberg \& Knoll, 1973). Specifically, the PSS corresponds to the SOA at which both target stimuli are equally often reported as having been presented first (e.g., 50\% "right stimulus presented first" responses). Thus, it marks the SOA at which both target stimuli subjectively appear simultaneously. For example, a PSS of 0 msec indicates that simultaneity is correctly perceived, because with an SOA of $0 \mathrm{msec}$, both target stimuli actually occur simultaneously. However, a shift of the PSS away from $0 \mathrm{msec}$ indicates a bias in perception - namely, that one of the target stimuli is processed faster than the other, and accordingly has to be presented later than the other in order to be perceived as simultaneous. Such shifts of the PSS have been repeatedly demonstrated; for example, as a result of directing attention to one of the stimuli and away from the other stimulus (Hikosaka, Miyauchi, \& Shimoyo, 1993; Schneider \& Bavelier, 2003; Shore, Spence, \& Klein, 2001; Stelmach \& Herdman, 1991). The JND, in contrast, reflects the smallest SOA between the two target stimuli that allows correct discrimination of temporal order. This time interval is located around the PSS and is usually defined as half the interquartile range of the psychometric function (see Sternberg \& Knoll, 1973). The steeper the psychometric function, the smaller is the JND. Therefore, high-discrimination performance, and thus, high temporal resolution, is associated with small values of JND.

Relevant evidence for the notion that temporal preparation influences temporal resolution was recently provided in a TOJ study by Correa, Sanabria, Spence, Tudela, and Lupiáñez (2006) within a temporal orienting paradigm. In contrast to the uninformative warning signal used to induce temporal preparation in standard foreperiod paradigms, temporal orienting paradigms employ either informative symbolic cues (e.g., Correa, Lupiáñez, \& Tudela, 2006; Miniussi, Wilding, Coull, \& Nobre, 1999) or blockwise instructions (e.g., Lange, Rösler, \& Röder, 2003) to induce expectancy of a certain foreperiod duration and, thus, direct participants' attention to the end of this foreperiod duration. An explicit cue, for example, might consist of the words early or late, indicating after which of two foreperiod durations (long or short) the target should be expected. Thus, the participant needs to interpret the symbolic cue in order to prepare for the expected moment of target occurrence and to direct attention to this moment. In addition, the validity of the temporal cue is manipulated. That is, foreperiods within each block of trials are mixed, so that in part of the trials, the cue corresponds to the actually presented foreperiod duration (valid cue), but in the remaining trials, the cue induces participants to expect the wrong foreperiod duration (invalid cue). It has been repeatedly shown that such explicit temporal cues enable participants to prepare endogenously for the presentation time of the target stimuli. For example, similar to preparation in standard foreperiod paradigms, motor as well as premotor variables are influenced by temporal orienting. Specifically, in valid trials, RT is reduced
(Correa, Lupiáñez, Milliken, \& Tudela, 2004), detection and discrimination performance is enhanced (Correa, Lupiáñez, \& Tudela, 2005; Wright \& Fitzgerald, 2004), and motor processing (Coull \& Nobre, 1998; Miniussi et al., 1999) as well as early auditory (e.g., Lange et al., 2003; Lange, Krämer, \& Röder, 2006; L. D. Sanders \& Astheimer, 2008) and visual potentials are enhanced (Correa, Lupiáñez, Madrid, \& Tudela, 2006; for an overview, see also Nobre, Correa, \& Coull, 2007). Temporal orienting paradigms are very useful, because they allow simultaneous investigation of the effects of directing attention to certain points in time and of variable foreperiod effects (e.g., Los \& Van den Heuvel, 2001).

In order to examine the influence of temporal orienting on the temporal resolution of visual perception, Correa, Sanabria, et al. (2006) combined such an explicit temporal cuing paradigm with a TOJ procedure. The results were clear-cut: When the explicit cue indicated the presentation time of the target stimuli validly, participants judged the order of the target stimuli more accurately than in invalid trials. In addition, when the foreperiod was short, JND was smaller for valid than for invalid trials. These results suggest that temporal orienting enhances the temporal resolution of visual perception. Independent of cue validity, the authors report that more correct responses were made after the long than after the short foreperiod. This result indicates that temporal resolution increases with foreperiod duration when foreperiod varies from trial to trial. Unfortunately, JND analyses for these conditions were not reported.

Given these results of a beneficial effect of temporal preparation in a temporal cuing context, one might expect a similar benefit of temporal preparation within a constant foreperiod design. However, there is some evidence that constant foreperiods might be less effective in influencing performance in temporal tasks than variable foreperiods. For example, within a variable foreperiod context, the duration of a stimulus is perceived as being longer following long than following short foreperiods, and, at least under certain conditions, duration judgments are also more accurate (Bendixen, Grimm, \& Schröger, 2006; Grondin \& Rammsayer, 2003; Mo \& George, 1977). In contrast, no such effects were found when constant foreperiods were employed (Grondin \& Rammsayer, 2003; Mo \& George, 1977). Thus, these studies indicate that constant foreperiods might be less effective in influencing performance in temporal tasks than variable foreperiods. As has been outlined above, different sources of uncertainty contribute to constant and variable foreperiod effects, and one might assume that these sources influence temporal perception differentially. Accordingly, it might be premature to generalize the beneficial effect of temporal orienting on temporal resolution obtained within the explicit cuing paradigm (Correa, Sanabria, et al., 2006) to constant foreperiod manipulations, in which only time uncertainty, but not expectancy, influences the preparatory process. Since relatively little is yet known about the specific processes underlying temporal preparation, it seems especially important to investigate this issue empirically. 


\section{EXPERIMENT 1}

We conducted a TOJ experiment to examine the influence of temporal preparation on temporal resolution within a constant foreperiod paradigm. In this paradigm, the two target stimuli for which the TOJ has to be performed are presented either after a short $(800-\mathrm{msec})$ or after a long $(2,400-\mathrm{msec})$ foreperiod. Thus, if the foreperiod is short, participants should be able to temporally prepare for the occurrence of the targets, whereas if the foreperiod is long, because of the increased time uncertainty, temporal preparation for the targets should be worse. Accordingly, if temporal preparation increases temporal resolution, TOJ performance should be better in the short foreperiod condition, and as a consequence, smaller JNDs should be obtained. However, unlike in spatial attention studies, in which attention usually is directed to one of the target stimuli and away from the other (Hikosaka et al., 1993; Schneider \& Bavelier, 2003; Shore et al., 2001; Stelmach \& Herdman, 1991; but see Hein et al., 2006), the two target stimuli are presented within a short time interval after a given foreperiod duration in the present experiment. Thus, within each foreperiod condition, participants should be equally temporally prepared for both target stimuli. Accordingly, neither of the two target stimuli should be perceived earlier than the other, and thus no influence of foreperiod duration on PSS is expected.

\section{Method}

Participants. Fourteen participants were recruited (6 male, mean age $=28.1$ years). They received either course credit or payment for their participation. All had normal or corrected-to-normal vision.

Stimuli and Apparatus. All stimuli were presented in white $\left(90 \mathrm{~cd} / \mathrm{m}^{2}\right)$ on a black background $\left(<1 \mathrm{~cd} / \mathrm{m}^{2}\right)$. Stimulus presentation was controlled via MATLAB, using the Psychophysics Toolbox extension (Brainard, 1997; Pelli, 1997). Participants were seated in a dimly lit room at a viewing distance of approximately $50 \mathrm{~cm}$ from the computer screen. The stimuli consisted of a fixation point $\left(0.1^{\circ}\right.$ visual angle), a square frame $\left(5.9^{\circ}\right)$, the target dots $\left(0.5^{\circ}\right)$, a square mask consisting of a random black-and-white-check pattern $\left(5.3^{\circ}\right)$, and a question mark $\left(0.6^{\circ} \times 1.1^{\circ}\right)$. Responses were collected using the "y" and "-" keys of a standard keyboard.
Procedure and Design. The time course of a single experimental trial is depicted in Figure 2. At the beginning of each trial, the screen remained empty for a variable interval of a random duration that followed an exponential distribution with a mean of 2,000 msec. This random duration is assumed to increase the functional significance of the warning signal (Müller-Gethmann et al., 2003). Then a fixation dot appeared at the center of the screen. It remained on the screen for $2,400 \mathrm{msec}$, in short foreperiod trials, or for $800 \mathrm{msec}$, in long foreperiod trials. ${ }^{3}$ Subsequently, the warning signal, a white frame, was added to the screen and stayed visible until the end of the trial. After a foreperiod duration of 800 or $2,400 \mathrm{msec}$, the fixation point disappeared, and one of the target dots appeared, equally likely on the left or on the right side of the center of the screen. The distance between the center and the dot position was $0.9^{\circ}$. After a variable SOA of $7,13,20,27$, or $33 \mathrm{msec}$, the second dot appeared on the opposite side of the screen center. The two dots remained on the screen for $100 \mathrm{msec}$ and were then replaced by the random check-pattern mask, which filled the warning signal frame. This mask was present for $500 \mathrm{msec}$. After the offset of the mask, a question mark appeared as a response signal in the center of the frame until there was a response or for a maximum duration of $2,000 \mathrm{msec}$. This temporally delayed response signal was introduced to discourage participants from speeded responding and, thus, to further minimize possible influences of motor processing on TOJ performance (e.g., by speed-accuracy trade-offs; Wickelgren, 1977). Participants had to indicate whether the left or the right dot had appeared first, using the index finger of their left or right hand, respectively. They were asked to respond as correctly as possible after the appearance of the question mark and were informed that response speed did not matter.

One experimental session consisted of 32 blocks with 20 trials each. After each block, participants received feedback about their percentage of correct responses. Although SOA (7, 13, 20, 27, or $33 \mathrm{msec}$ ) varied randomly between trials, each foreperiod duration ( 800 vs. $2,400 \mathrm{msec}$ ) was kept constant across the trials of 16 consecutive blocks. The order of the two foreperiod conditions was balanced across participants. The first block of each foreperiod condition was considered practice and was therefore discarded from data analysis. Trials in which no response key had been pressed within $2,000 \mathrm{msec}$ following the appearance of the question mark were discarded from data analysis (1.6\%).

\section{Results and Discussion}

The data of 3 participants with performance close to chance level were discarded from data analysis, because for these participants, the fitted psychometric func-

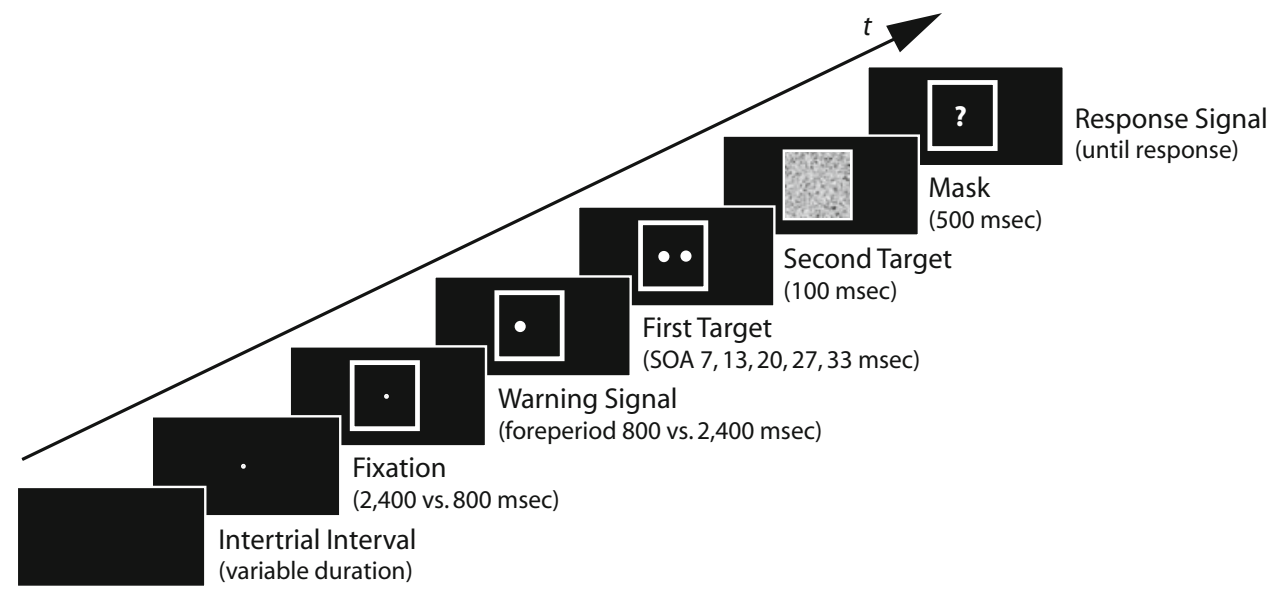

Figure 2. Time course of a single experimental trial in Experiment 1. 
tions revealed estimations of JND values clearly above $100 \mathrm{msec}$, a value far beyond the range of the actually presented SOAs.

Percent correct. A repeated measures ANOVA with the factors SOA and foreperiod duration was conducted on mean percentage of correct responses (PC). When appropriate, $p$ values were adjusted for violations of the sphericity assumption using the Greenhouse-Geisser correction. This analysis revealed a main effect of SOA $\left[F(4,40)=60.33, p<.001, \eta^{2}=.86\right]$, indicating more correct responses as the interval between the two target dots increased. Crucially, the manipulation of temporal preparation also influenced $\mathrm{PC}$, with shorter foreperiods yielding more correct responses $[F(1,10)=10.13, p<$ $\left..01, \eta^{2}=.50\right]$. This effect was not influenced by SOA $[F(4,40)=0.67, p=.599]$ (see Figure 3).

JND and PSS. To estimate JND and PSS for each participant and foreperiod duration, we computed the proportion of "right dot presented first" responses at each SOA level, whereas SOA levels now were defined as ranging from $-33 \mathrm{msec}$ (left dot preceded right dot) to $+33 \mathrm{msec}$ (right dot preceded left dot). Then, we employed a maximum likelihood procedure to estimate the PSS and the JND, which maximized the likelihood for the following logistic psychometric function (Bush, 1963):

$$
P(\text { “right dot first" } \mid \mathrm{SOA})=\frac{1}{1+e^{-(\mathrm{SOA}-\mathrm{PSS}) /(0.91 \cdot \mathrm{JND})}} \text {. }
$$

A paired-samples $t$ test on the JND estimations clearly revealed better performance for short than for long foreperiods $\left[t(10)=2.58, p<.05, \eta^{2}=.40 ; \mathrm{JND}=20.1 \mathrm{vs}\right.$. $32.0 \mathrm{msec}$, respectively]. Thus, participants in the short foreperiod condition needed a shorter SOA duration to obtain a $75 \%$ correct level of temporal order discrimination. As expected, PSS in the short foreperiod condition $(2.1 \mathrm{msec})$ did not differ from PSS in the long foreperiod condition $(4.4 \mathrm{msec})[t(10)=0.95, p=.366]$.

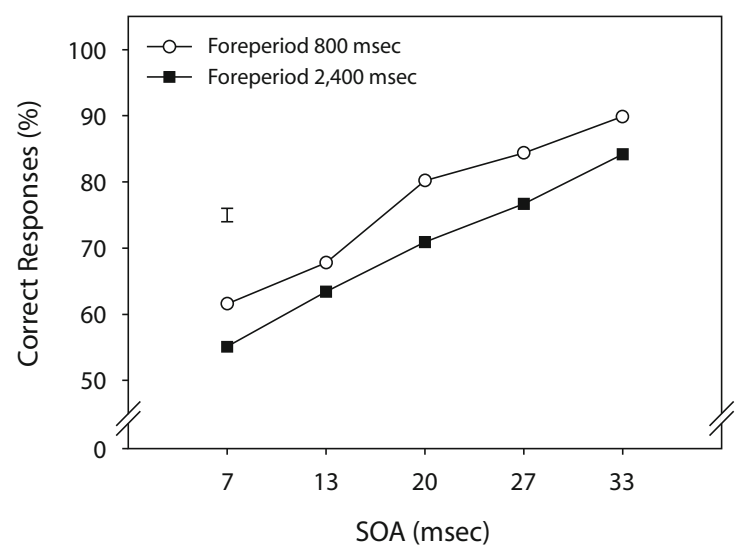

Figure 3. Mean percentages of correct responses in Experiment 1 depicted as a function of stimulus onset asynchrony (SOA) and foreperiod duration. The error bar provides the standard error of the mean, which was computed from the pooled error terms of the corresponding ANOVA according to a suggestion made by Loftus (2002).
The higher percentage of correct responses as well as the smaller JND associated with short foreperiods clearly indicate improved TOJ when participants were able to predict the moment of stimulus occurrence accurately. This effect suggests that temporal preparation within a constant foreperiod paradigm improves the temporal resolution of visual perception.

These results are consistent with those of Correa, Sanabria, et al. (2006), who found evidence for improved temporal resolution within an explicit temporal cuing paradigm. Thus, there is no evidence for a dissociation between temporal preparation within a constant foreperiod and within a temporal orienting paradigm. Despite the possibility that different sources of uncertainty - namely, time uncertainty and expectancy - contribute to the effects of constant foreperiods and temporal orienting, a similar preparatory mechanism might underlie those effects.

The present experiment assessed TOJ performance in a task that required processing of the stimulus location to enable judgments about stimulus order. This might constrain the interpretation of the results as being solely due to enhanced temporal resolution. In particular, Doherty, Rao, Mesulam, and Nobre (2005) have shown that temporal preparation can also enhance processing of spatial stimulus location. These authors presented a ball that moved from left to right across a computer screen. This ball disappeared behind a vertical bar on the screen, and reappeared again on the other side of the bar. When the ball reappeared, participants had to detect whether it contained a black dot or not, and to respond as fast as possible if the dot was present. Importantly, in one condition, the ball moved in a linear trajectory over the screen, enabling participants to build up spatial expectations about the location at which the ball would reappear. In another condition, the ball "jumped" across the screen, thus preventing spatial expectations. In addition, the ball could either move at regular or irregular temporal intervals, enabling participants to build up, or hindering them from building up, temporal expectancies about when the ball would reappear. The authors found some evidence for a synergistic effect of spatial and temporal expectations. Although temporal expectations alone had no effect on the amplitude of the P1 (an ERP component reflecting early perceptual processing), combined spatial and temporal expectations yielded a higher P1 amplitude than did spatial expectations alone. A similar tendency was present in their RT results. In trials with combined spatial and temporal expectations, RT was slightly reduced in comparison with spatial expectation alone, and significantly reduced compared with temporal expectations alone. Thus, enabling temporal expectations about a stimulus might enhance the efficiency of building up expectations about the spatial location of this stimulus, or it might facilitate directing visual attention to the expected stimulus location. Against the background of this study, the present results might be interpreted in a different way. Accordingly, rather than mirroring enhanced temporal resolution in the good temporal preparation condition, the results might be partly due to an enhanced effect of temporal preparation on the processing of spatial stimulus location. In other words, 
temporal preparation might have merely facilitated localization of the target stimuli and thus improved judgments of the location of the stimulus presented first. Accordingly, improved TOJ performance associated with good temporal preparation might not be the result of enhanced temporal resolution per se, but might reflect improved location processing. Experiment 2 was designed to rule out this alternative explanation.

\section{EXPERIMENT 2}

This experiment aimed at decoupling the effect of temporal preparation on temporal resolution from potential effects of temporal preparation on location processing (Doherty et al., 2005). Thus, in contrast to Experiment 1, which required participants to indicate the temporal order of the presented stimuli by identifying the location of the stimulus presented first, in Experiment 2 participants were asked about the identity of the stimulus presented first. Both target stimuli were now presented spatially overlapping at the center of the screen. Thus, because the location of both target stimuli was identical, this stimulus arrangement ensured that location processing was irrelevant for performing the TOJ task.

\section{Method}

Participants. Fourteen participants were recruited ( 2 male, mean age $=25.2$ years). They participated for course credit or payment. All had normal or corrected-to-normal vision.

Stimuli and Apparatus. Again, all stimuli were presented in white $\left(90 \mathrm{~cd} / \mathrm{m}^{2}\right)$ on a black background $\left(<1 \mathrm{~cd} / \mathrm{m}^{2}\right)$ and participants were seated in a dimly lit room at a viewing distance of approximately $50 \mathrm{~cm}$ from the computer screen. A plus sign and a multiplication sign (both $1.3^{\circ}$ visual angle) served as target stimuli. Thus, the two different target stimuli were identical except for their spatial orientation (specifically, the multiplication sign was the plus sign tilted by $45^{\circ}$ ). All other stimuli were identical with those employed in Experiment 1. Responses were collected via the right and left shift keys of a standard keyboard.

Procedure and Design. The course of a single trial is depicted in Figure 4. It was identical to trials in Experiment 1, except for the following changes. First, following the foreperiod, one of the two target stimuli was presented in the center of the screen. After a variable $\mathrm{SOA}$, this stimulus was superimposed by the second target stimulus, thus forming the image of a star, which remained on the screen for $100 \mathrm{msec}$ before being masked. Second, SOA durations were prolonged to $27,33,40,47$, and $53 \mathrm{msec}$, because pretesting indicated that TOJ for this stimulus arrangement was more difficult than in Experiment 1. Third, for the same reason, maximum RT was increased to 3,000 msec. Participants had to indicate whether the plus or the multiplication sign had appeared first, using the index finger of their left or right hand, respectively. As in Experiment 1, trials in which no response key had been pressed were discarded from data analysis $(0.9 \%)$.

\section{Results and Discussion}

Percent correct. An ANOVA on PC revealed a main effect of SOA $\left[F(4,52)=48.32, p<.001, \eta^{2}=.79\right]$, indicating more correct responses as the interval between the two target stimuli increased. The manipulation of temporal preparation also influenced $\mathrm{PC}$, with shorter foreperiods yielding more correct responses $[F(1,13)=17.98, p=$ $\left..001, \eta^{2}=.58\right]$. This effect was not influenced by SOA $[F(4,52)=0.64, p=.578]$ (see Figure 5).

JND and PSS. JND and PSS for each participant and foreperiod duration were computed as in Experiment 1. First, we collected the proportion of "multiplication sign presented first" responses at each SOA level, now defined as ranging from $-53 \mathrm{msec}$ (plus sign preceded multiplication sign) to $+53 \mathrm{msec}$ (multiplication sign preceded plus sign). Then, we again employed a maximum likelihood procedure to estimate PSS and JND. A paired-samples $t$ test for JND showed better performance for short foreperiods than for long foreperiods $[t(13)=4.11, p=$ $\left..001, \eta^{2}=.57\right]$ (JND $=17.8$ vs. 22.4 msec, respectively). Again, PSS did not differ between the short and long foreperiod conditions $[t(13)=1.29, p=.219](\mathrm{PSS}=-2.0$ vs. $1.4 \mathrm{msec}$, respectively).

These results argue strongly for a higher temporal resolution of visual perception when participants can precisely prepare for the moment of target presentation within a constant foreperiod design. This improvement, however, seems not to be due to a facilitation of location processing

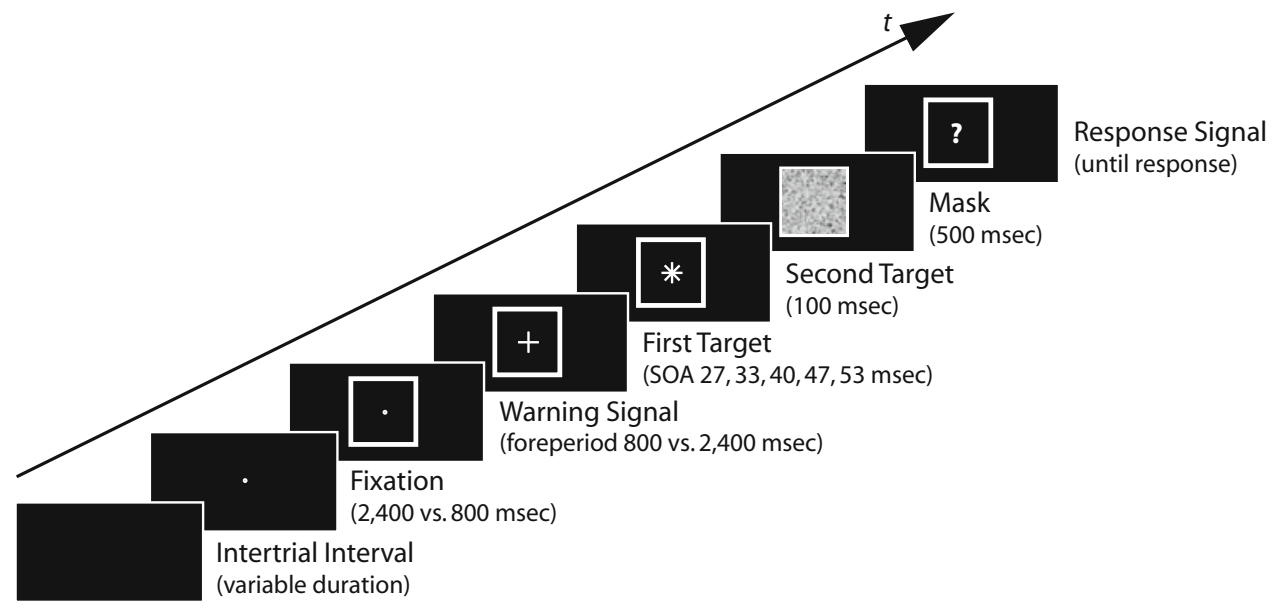

Figure 4. Time course of a single experimental trial in Experiment 2. 


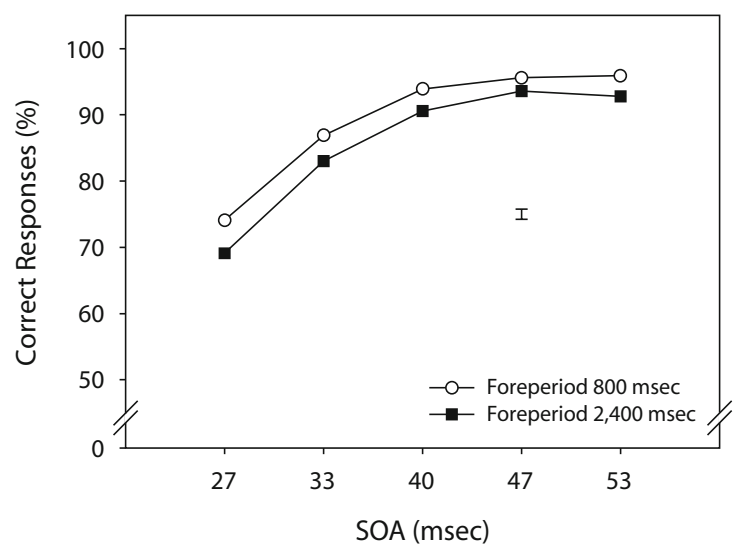

Figure 5. Mean percentages of correct responses in Experiment 2, depicted as a function of stimulus onset asynchrony (SOA) and foreperiod duration. The error bar provides the standard error of the mean, which was computed from the pooled error terms of the corresponding ANOVA according to a suggestion made by Loftus (2002).

by temporal preparation (cf. Doherty et al., 2005), since in Experiment 2 the spatial location of both target stimuli was identical and irrelevant for the selection of the correct response.

\section{EXPERIMENT 3}

The results of Experiments 1 and 2 in combination with the results of Correa, Sanabria, et al. (2006) provide converging evidence for an enhancement of temporal processing when participants can temporally prepare for target presentation. The present experiments, and also the study of Correa, Sanabria, et al. (2006), however, employed only two different foreperiod durations. In order to investigate the time course of temporal preparation, Experiment 3 aimed at generalizing these results to a wide range of foreperiod durations. ${ }^{4}$ To this end, we basically replicated Experiment 1 but employed foreperiod durations ranging from 150 to $4,800 \mathrm{msec}$. As outlined in the introduction, RTs usually increase with increasing foreperiod duration in a constant foreperiod design, reflecting the increasing time uncertainty about the moment of target occurrence. This pattern can be found over a rather broad range of foreperiods, with the exception of very short foreperiods. Specifically, at short foreperiods up to approximately $200 \mathrm{msec}$, RT usually decreases with increasing foreperiod duration, and when a wide range of foreperiods is employed, RTs follow a U-shaped function (e.g., Bertelson \& Tisseyre, 1969; Müller-Gethmann et al., 2003). This time course has been interpreted as evidence that the buildup of temporal preparation takes some time, and it has been suggested that foreperiod effects of very short foreperiods might instead be due to the arousing properties of the warning signal (e.g., Hackley \& Valle-Inclán, 2003; Ulrich \& Mattes, 1996). Importantly, Müller-Gethmann et al. found this U-shaped pattern of foreperiod effects not only in RT but also in the stimulus-locked lateralized readiness potential (S-LRP), a component that is thought to index the duration of premotor processes. It is unclear, however, whether this characteristic time course of temporal preparation generalizes to accuracy measures, such as the JND in a TOJ task.

\section{Method}

Participants. Thirty participants were recruited ( 8 male, mean age $=26.07$ years). All had normal or corrected-to-normal vision.

Stimuli and Apparatus. All stimuli were identical to those employed in Experiment 1.

Procedure and Design. The course of each trial was similar to trials in Experiment 1, with the following exceptions. First, we employed six different foreperiod durations $(150,300,600,1,200$, 2,400 , and $4,800 \mathrm{msec}$ ). Second, following the intertrial interval, the fixation dot was presented for $4,950 \mathrm{msec}$ minus the foreperiod duration of the current block. Thus, overall trial duration was again kept constant, irrespective of the foreperiod duration of the current block. Third, the method of constant stimuli was replaced by an adaptive, weighted up-down procedure (Kaernbach, 1991). In more detail, within each foreperiod block, two randomly interleaved runs with 60 trials each were presented to estimate the 25th (lower run) and the 75th (upper run) percentiles of the psychometric function (see also Lapid, Ulrich, \& Rammsayer, 2008). In the first trial of the lower run, the left target dot was presented $40 \mathrm{msec}$ before the right dot $(\mathrm{SOA}=-40 \mathrm{msec})$, and in the first trial of the upper run, the right target dot was presented $40 \mathrm{msec}$ before the left dot $(\mathrm{SOA}=+40 \mathrm{msec})$. In the following trials, this SOA value was changed according to an adaptive rule (see Kaernbach, 1991). After a "right dot presented first" response, SOA duration for the next trial of the respective run was decreased by either $20 \mathrm{msec}$ (lower run) or by $6.6 \mathrm{msec}$ (upper run). After a "left dot presented first" response, SOA duration was increased by $6.6 \mathrm{msec}$ (lower run) or by $20 \mathrm{msec}$ (upper run). If no key was pressed within the maximum RT of 2,000 msec, the trial was excluded from later data analysis, and the present SOA duration was repeated in the next trial of the respective run.

Each participant completed 120 trials within each of the six foreperiod conditions. The order of these foreperiod blocks was balanced across participants according to an even Latin square. No performance feedback was provided, but after every 30 trials a break allowed participants to rest. The first 30 trials in each foreperiod block were considered practice and were discarded from further analysis.

\section{Results and Discussion}

The adaptive, weighted up-down procedure employed here tracks the SOA durations down to the 25 th and 75 th percentiles of each participant's underlying psychometric function. Accordingly, independent of individual differences and experimental conditions, performance always approximately corresponds to $75 \%$ correct responses. Thus, in the following, only the results for JND and PSS are reported. These two variables were computed for each participant and foreperiod duration as in Experiment 1. A repeated measures ANOVA with factor foreperiod duration was conducted on JND and PSS.

The ANOVA on JND revealed a small but significant main effect of foreperiod duration $[F(5,145)=2.90$, $\left.p<.05, \eta^{2}=0.09\right]$. As can be seen in Figure 6, JND values show a U-shaped dependency on foreperiod duration similar to that typically observed for RT data. In contrast to JND, PSS did not depend on foreperiod duration $[F(5,145)=0.87, p=.451]$. These results replicate the beneficial effect of temporal preparation on temporal resolution within a constant foreperiod paradigm found in 


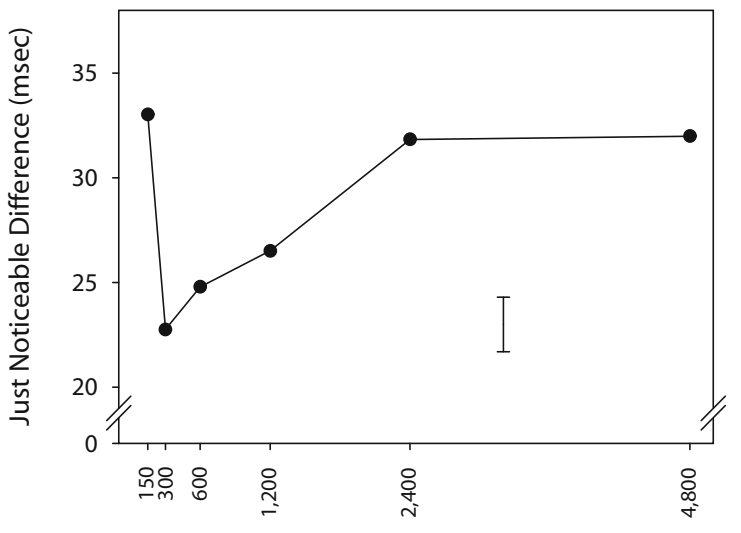

Foreperiod Duration (msec)

Figure 6. Mean estimated just noticeable differences in Experiment 3, depicted as a function of foreperiod duration. The error bar provides the standard error of the mean, which was computed from the pooled error terms of the corresponding ANOVA according to a suggestion made by Loftus (2002).

the previous experiments, and extend it to a wider range of foreperiod durations. The observed pattern of results is highly consistent with those previously found for RT (Bertelson \& Tisseyre, 1969) and for the S-LRP data (Müller-Gethmann et al., 2003). To our knowledge, this is the first demonstration of this typical U-shaped pattern for an accuracy measure in a perceptual task. The pattern indicates that temporal preparation in a constant foreperiod paradigm needs some time to develop fully. Specifically, the optimal state of preparation in our experiment seems to be reached after $300 \mathrm{msec}$ of preparatory processing. This remarkable similarity between the effects of constant foreperiods on RT and JND points to a common preparatory mechanism that applies to both latency and accuracy measures of performance.

\section{GENERAL DISCUSSION}

The present experiments were designed to investigate the influence of temporal preparation within a constant foreperiod paradigm on the temporal resolution of visual perception. To this end, we conducted three experiments measuring TOJ performance. In Experiments 1 and 2, two different foreperiod durations were employed. Both experiments clearly showed improved performance when the foreperiod was short and participants thus were able to prepare for the exact time of target presentation. Specifically, more correct responses and lower JND were observed in the short than in the long foreperiod condition. Experiment 3 employed a wide range of foreperiod durations. Interestingly enough, the pattern of results that was found for JND resembles the one that is usually observed for latency measures such as RT. For short foreperiods $(<300 \mathrm{msec})$, performance increases as the foreperiod duration increases. For longer foreperiods, however, performance becomes worse as the foreperiod duration is lengthened. This U-shaped pattern indicates that building up temporal preparation is time-consuming. Since TOJ performance depends mainly on perceptual processing and not on motor processes, our results argue strongly for a perceptual locus of temporal preparation. The results therefore corroborate the facilitating influence of temporal preparation on perceptual processing found in previous studies employing either constant foreperiod designs (Bausenhart et al., 2007; Rolke, in press; Rolke \& Hofmann, 2007) or temporal orienting studies (e.g., Correa et al., 2005; Lange et al., 2003).

Moreover, the present results show that within a constant foreperiod design, TOJ is enhanced by temporal preparation. This result is consistent with a similar effect obtained by Correa, Sanabria, et al. (2006) within an explicit temporal cuing paradigm. However, the results of Experiment 1 and also those obtained by Correa, Sanabria, et al. might be due to improved location processing rather than to enhanced temporal resolution. Therefore, we conducted Experiment 2, in which the judgment of temporal order did not require location processing, but depended solely on the processing of stimulus identity. Since this second experiment replicated the beneficial effect of temporal preparation, the alternative interpretation - that processing of stimulus location is enhanced when participants are temporally prepared-seems less plausible.

Given this enhancement in temporal resolution, one might ask why no effects of constant foreperiods on duration judgments were found by Mo and George (1977) or by Grondin and Rammsayer (2003). For example, according to countermodels of time perception, one might expect that enhanced temporal resolution is the result of a higher neural pulse rate, and thus, comes along with longer duration judgments (e.g., Rammsayer \& Ulrich, 2001). The fact that no such effects were reported, however, might be well explained by methodological characteristics of the single stimulus presentation procedure employed to investigate duration judgments. For example, Mo and George presented in each trial a visual stimulus of either 500-msec or 550-msec duration, and participants then had to decide whether the long or the short stimulus had been presented. In the constant-foreperiod condition, this procedure might have masked a potential foreperiod effect on perceived duration. Specifically, as a result of good temporal preparation, the stimuli in the short foreperiod block might have been perceived as being longer than in the long foreperiod block. However, within each of the foreperiod blocks, the 550-msec stimulus would still be perceived as being longer than the 500-msec stimulus. Accordingly, the required "shorter/longer" decision would be unaffected by foreperiod duration. In the experiments of Grondin and Rammsayer, several modifications might have made this explanation less valid. First, participants had to memorize a given standard duration at the beginning of the experiment. Then, in each trial, one of several different comparison stimulus durations was presented, and participants had to judge whether the comparison was longer or shorter than the memorized standard duration. Even this procedure might be problematic, however, since it has been recently proposed that internalized standard durations might also be influenced by the duration of the 
stimuli presented in previous trials (see Lapid et al., 2008). Thus, if a short foreperiod causes the comparisons to be perceived as longer, this might also prolong the internal representation of the standard duration. As a consequence, the "longer/shorter than standard" judgments would also remain relatively unchanged by foreperiod duration. In addition, foreperiod duration was manipulated as a betweensubjects variable, and the range of employed foreperiods was rather small (300-600 msec). In our Experiment 3, this range of foreperiods produced only a small increase in observed JND as well. In sum, possible influences of foreperiod duration on perceived duration and on the accuracy of duration discrimination might have been rather underestimated by previous studies.

The present study shows that temporal preparation enhances the temporal resolution of visual perception. This result strengthens the assumption that temporal preparation exerts its influence at a perceptual processing level. However, the question about the specific mechanism that underlies this perceptual effect remains open. To explain the influence of temporal preparation on the spatial resolution within a perceptual discrimination task, Rolke and Hofmann (2007) proposed a model that explicitly refers to the preparation-based modulation of perceptual processing. This model is based on the assumption that during perceptual stimulus processing, external stimulus information is translated into internal activation that is accumulated over time. As soon as this activation reaches a criterion level, a decision is made and a response is initiated (cf. Luce, 1986). To account for temporal preparation effects on perception, Rolke and Hofmann proposed that if participants can estimate the time of the onset of a stimulus exactly, and thus are prepared for the time of stimulus occurrence, perceptual processing of this stimulus starts earlier. Therefore, under conditions that allow good temporal preparation, a higher level of accumulated activation would be reached by the time that stimulus processing becomes interrupted - for example, by a masking stimulus (Kahneman, 1968; Sperling, 1963). This account predicts that temporal preparation improves accuracy of stimulus detection and discrimination, because postperceptual decision processes are supplied with more relevant stimulus information under high levels of temporal preparation. In addition, shorter RT should be observed when participants are temporally prepared, because the criterion level would be reached earlier and thus, response selection and execution could start - and accordingly, would be finishedearlier. Thus, this model can account for a variety of findings obtained with different manipulations of temporal preparation and within different task situations.

To account for the facilitating effect of temporal preparation on TOJ, however, one might assume that temporal preparation provokes a higher rate of perceptual information sampling, thereby increasing the temporal resolution (see also Correa, Sanabria, et al., 2006). Since more information samples are collected during perceptual analysis of stimuli for which one is temporally prepared, this enhanced sampling rate would accelerate the accumulation of stimulus information within the perceptual system.
So far, research on temporal preparation does not provide any evidence concerning the question of whether the early onset hypothesis by Rolke and Hofmann (2007) or the increased rate of information sampling contribute to the effects of temporal preparation. Further research should aim at disentangling those distinct but not mutually exclusive mechanisms and at uncovering their respective contributions to the effect of temporal preparation on perceptual processing.

To summarize, the present experiments show enhanced temporal resolution for the perception of visual stimuli within a constant foreperiod design. This effect seems to be independent of specific task requirements, since it was observed when decisions about the temporal order of two successively appearing stimuli had to be based on either stimulus location or stimulus identity. In addition, the time course of preparation in this perceptual task closely follows the typically U-shaped function previously observed for latency measures. These facilitating effects of temporal preparation might be due to a higher rate of information sampling in the perceptual system associated with temporal preparation.

\section{AUTHOR NOTE}

This study was supported by Grant RO3034 of the German Research Foundation (DFG). We thank Verena Seibold and Thilo Rommel for their assistance in data acquisition and Jennifer Coull and two anonymous reviewers for their helpful comments. Correspondence should be addressed to K. M. Bausenhart, Psychologisches Institut, University of Tübingen, Friedrichstrasse 21, D-72072 Tübingen, Germany (e-mail: karin.bausenhart@uni-tuebingen.de).

\section{REFERENCES}

Bausenhart, K. M., Rolke, B., Hackley, S. A., \& Ulrich, R. (2006). The locus of temporal preparation effects: Evidence from the psychological refractory period paradigm. Psychonomic Bulletin \& Review, 13, 536-542.

Bausenhart, K. M., Rolke, B., \& Ulrich, R. (2007). Knowing when to hear aids what to hear. Quarterly Journal of Experimental Psychology, 60, 1610-1615.

Bendixen, A., Grimm, S., \& Schröger, E. (2006). The relation between onset, offset, and duration perception as examined by psychophysical data and event-related brain potentials. Journal of Psychophysiology, 20, 40-51.

Bertelson, P., \& Tisseyre, F. (1969). The time-course of preparation: Confirmatory results with visual and auditory warning signals. Acta Psychologica, 30, 145-154.

Brainard, D. H. (1997). The Psychophysics Toolbox. Spatial Vision, 10, 433-436.

Brunia, C. H. M., Scheirs, J. G. M., \& HaAgh, S. A. V. M. (1982). Changes of Achilles tendon reflex amplitudes during a fixed foreperiod of four seconds. Psychophysiology, 19, 63-70.

Bush, R. R. (1963). Estimation and evaluation. In R. D. Luce, R. R. Bush, \& E. Galanter (Eds.), Handbook of mathematical psychology: Vol. 1 (pp. 429-469). New York: Wiley.

Correa, Á., Lupiáñez, J., Madrid, E., \& Tudela, P. (2006). Temporal attention enhances early visual processing: A review and new evidence from event-related potentials. Brain Research, 1076, 116-128.

Correa, Á., Lupiáñez, J., Milliken, B., \& Tudela, P. (2004). Endogenous temporal orienting of attention in detection and discrimination tasks. Perception \& Psychophysics, 66, 264-278.

Correa, Á., LupiáñEZ, J., \& Tudela, P. (2005). Attentional preparation based on temporal expectancy modulates processing at the perceptual level. Psychonomic Bulletin \& Review, 12, 328-334.

Correa, Á., Lupiáñez, J., \& Tudela, P. (2006). The attentional mecha- 
nism of temporal orienting: Determinants and attributes. Experimental Brain Research, 169, 58-68.

Correa, Á., Sanabria, D., Spence, C., Tudela, P., \& Lupiáñez, J. (2006). Selective temporal attention enhances the temporal resolution of visual perception: Evidence from a temporal order judgment task. Brain Research, 1070, 202-205.

Coull, J. T., \& NoBre, A. C. (1998). Where and when to pay attention: The neural systems for directing attention to spatial locations and to time as intervals as revealed by both PET and fMRI. Journal of Neuroscience, $\mathbf{1 8}, 7426-7435$.

Doherty, J. R., Rao, A., Mesulam, M. M., \& Nobre, A. C. (2005). Synergistic effect of combined temporal and spatial expectations on visual attention. Journal of Neuroscience, 25, 8259-8266.

DrazIN, D. H. (1961). Effects of foreperiod, foreperiod variability, and probability of stimulus occurrence on simple reaction time. Journal of Experimental Psychology, 62, 43-50.

GaIllard, A. W., \& NÄÄTÄNEN, R. (1973). Slow potential changes and choice reaction time as a function of interstimulus interval. Acta Psychologica, 37, 173-186.

Grondin, S., \& RAMmSAYER, T. (2003). Variable foreperiods and temporal discrimination. Quarterly Journal of Experimental Psychology, 56A, 731-765.

Hackley, S. A., Schankin, A., Wohlschlaeger, A., \& Wascher, E. (2007). Localization of temporal preparation effects via trisected reaction time. Psychophysiology, 44, 334-338.

HACKLEY, S. A., \& VALLE-INCLÁN, F. (2003). Which stages of processing are speeded by a warning signal? Biological Psychology, 64, 27-45.

HasbroucQ, T., Kaneko, H., Akamatsu, M., \& Possamaï, C.-A. (1997). Preparatory inhibition of cortico-spinal excitability: A transcranial magnetic stimulation study in man. Cognitive Brain Research, 5, 185-192.

Hein, E., Rolke, B., \& Ulrich, R. (2006). Visual attention and temporal discrimination: Differential effects of automatic and voluntary cueing. Visual Cognition, 13, 29-50.

Hikosaka, O., Miyauchi, S., \& Shimoyo, S. (1993). Focal visual attention produces illusory temporal order and motion sensation. Vision Research, 33, 1219-1240.

KAERNBACH, C. (1991). Simple adaptive testing with the weighted updown method. Perception \& Psychophysics, 49, 227-229.

Kahneman, D. (1968). Method, findings, and theory in studies of visual masking. Psychological Bulletin, 70, 404-425.

KARLIN, L. (1959). Reaction time as a function of foreperiod duration and variability. Journal of Experimental Psychology, 58, 185-191.

KLEMmer, E. T. (1956). Time uncertainty in simple reaction time. Journal of Experimental Psychology, 51, 179-184.

Lange, K., Krämer, U. M., \& RöDER, B. (2006). Attending points in time and space. Experimental Brain Research, 173, 130-140.

LANGE, K., RösleR, F., \& RöDER, B. (2003). Early processing stages are modulated when auditory stimuli are presented at an attended moment in time: An event-related potential study. Psychophysiology, $\mathbf{4 0}$ 806-817.

LAPID, E., UlRich, R., \& RAMmSAYER, T. (2008). On estimating the difference limen in duration discrimination tasks: A comparison of the $2 \mathrm{AFC}$ and the reminder task. Perception \& Psychophysics, 70, 291-305.

Loftus, G. R. (2002). Analysis, interpretation, and visual presentation of experimental data. In H. Pashler (Ed.), Stevens' handbook of experimental psychology. New York: Wiley.

Los, S. A., KNoL, D. L., \& Boers, R. M. (2001). The foreperiod effect revisited: Conditioning as a basis for nonspecific preparation. Acta Psychologica, 106, 121-145.

Los, S. A., \& VAN DEN Heuvel, C. E. (2001). Intentional and unintentional contributions to nonspecific preparation during reaction time foreperiods. Journal of Experimental Psychology: Human Perception \& Performance, 27, 370-386.

LOVELESS, N. E., \& SANFord, A. J. (1974). Slow potential correlates of preparatory set. Biological Psychology, 1, 303-314.

LUCE, R. D. (1986). Response times: Their role in inferring elementary mental organization. New York: Oxford University Press.

Mattes, S., \& Ulrich, R. (1997). Response force is sensitive to the temporal uncertainty of response stimuli. Perception \& Psychophysics, 59, 1089-1097.
Miniussi, C., Wilding, E. L., Coull, J. T., \& Nobre, A. C. (1999). Orienting attention in time: Modulation of brain potentials. Brain, 122, 1507-1518.

Mo, S. S., \& GEORGE, E. J. (1977). Foreperiod effects on time estimation and simple reaction time. Acta Psychologica, 41, 47-59.

Müller-Gethmann, H., Ulrich, R., \& Rinkenauer, G. (2003). Locus of the effect of temporal preparation: Evidence from the lateralized readiness potential. Psychophysiology, 40, 597-611.

NÄ̈̈TÄNEN, R. (1970). The diminishing time-uncertainty with the lapse of time after the warning signal in reaction-time experiments with varying fore-periods. Acta Psychologica, 34, 399-419.

NÄÄTÄNEN, R. (1971). Non-aging fore-periods and simple reaction time. Acta Psychologica, 35, 316-327.

NäÄTänen, R., Muranen, V., \& Merisalo, A. (1974). Timing of expectancy peak in simple reaction time situation. Acta Psychologica, 38, 461-470.

Nickerson, R. S., \& Burnham, D. W. (1969). Response times with nonaging foreperiods. Journal of Experimental Psychology, 79, 452-457.

NIEMI, P., \& NÄÄTÄNEN, R. (1981). Foreperiod and simple reaction time. Psychological Bulletin, 89, 133-162.

Nobre, A. C., Correa, A., \& Coull, J. T. (2007). The hazards of time. Current Opinion in Neurobiology, 17, 465-470.

Pelli, D. G. (1997). The VideoToolbox software for visual psychophysics: Transforming numbers into movies. Spatial Vision, 10, 437-442.

Rammsayer, T., \& Ulrich, R. (2001). Counting models of temporal discrimination. Psychonomic Bulletin \& Review, 8, 270-277.

Requin, J., Bonnet, M., \& Semuen, A. (1977). Is there a specificity in the supraspinal control of motor structures during preparation? In S. Dornic (Ed.), Attention and performance VI (pp. 139-174). Hillsdale, NJ: Erlbaum.

ROLKE, B. (in press). Temporal preparation facilitates perceptual identification of letters. Perception \& Psychophysics.

Rolke, B., \& Hofmann, P. (2007). Temporal uncertainty degrades perceptual processing. Psychonomic Bulletin \& Review, 14, 522-526.

SANDERS, A. F. (1980). Some effects of instructed muscle tension on choice reaction time and movement time. In R. S. Nickerson (Ed.), Attention and performance VIII (pp. 59-74). Hillsdale, NJ: Erlbaum.

SAnders, L. D., \& Astheimer, L. B. (2008). Temporally selective attention modulates early perceptual processing: Event-related potential evidence. Perception \& Psychophysics, 70, 732-742.

SCHNeIder, K. A., \& BAVELIER, D. (2003). Components of visual prior entry. Cognitive Psychology, 47, 333-366.

Shore, D. I., Spence, C., \& Klein, R. M. (2001). Visual prior entry. Psychological Science, 12, 205-212.

Sperling, G. (1963). A model for visual memory tasks. Human Factors, 5, 19-31.

Stelmach, L. B., \& Herdman, C. M. (1991). Directed attention and perception of temporal order. Journal of Experimental Psychology: Human Perception \& Performance, 17, 539-550.

STERnBERG, S., \& KNOLL, R. L. (1973). The perception of temporal order: Fundamental issues and a general model. In S. Kornblum (Ed.), Attention and performance IV (pp. 629-685). New York: Academic Press.

Trillenberg, P., Verleger, R., Wascher, E., Wauschiuhn, B., \& WESSEL, K. (2000). CNV and temporal uncertainty with "ageing" and "non-ageing" S1-S2 intervals. Clinical Neurophysiology, 111, 1216-1226.

UlRich, R., \& Mattes, S. (1996). Does immediate arousal enhance response force in simple reaction time? Quarterly Journal of Experimental Psychology, 49A, 972-990.

WICKELGREN, W. A. (1977). Speed-accuracy tradeoff and information processing dynamics. Acta Psychologica, 41, 67-85.

Woodrow, H. (1914). The effect upon reaction time of variation in the preparatory interval. In J. Angell, H. Warren, J. Watson, \& S. Franz (Eds.), The psychological monographs (pp. 16-65). Princeton, NJ: Psychological Review Co.

Wright, B. A., \& Fitzgerald, M. B. (2004). The time course of attention in a simple auditory detection task. Perception \& Psychophysics, 66, 508-516.

YeshuRun, Y., \& Levy, L. (2003). Transient spatial attention degrades temporal resolution. Psychological Science, 14, 225-231. 


\section{NOTES}

1. Throughout this article, the term temporal preparation will be used to describe preparatory activity that is directed at the moment of target presentation, in order to facilitate processing of the target. This preparatory activity, however, is unspecific regarding specific task requirements or stimulus properties. Accordingly, temporal preparation refers to the temporal precision of preparatory processes, and should not be interpreted as specific preparation for performing temporal tasks (as, e.g., temporal order judgments).

2. A competing theoretical account of the preparation process is based on a mechanism of trace conditioning (Los, Knol, \& Boers, 2001; Los \& Van den Heuvel, 2001). This account assumes that a warning signal serves as a conditioned stimulus, which automatically triggers the development of response-related activation during the foreperiod. In a constant foreperiod design, after a few trials of learning, this activation is assumed to peak at the moment of the presentation of the target stimulus. In addition, these authors assume that the asymptote of this activation peak decreases with increasing foreperiod, thereby reflecting a decrement in the preparatory state. In variable foreperiod designs, in a given trial, the strength of the conditioned activation for each of the possible moments of target presentation changes according to the foreperiod that was presented in the previous trial. If, for example, the foreperiod in trial $n-1$ is long, the activation in the next trial $(n)$ would be high at the end of the long foreperiod according to this conditioning view. If in trial $n$, how- ever, a short foreperiod is presented, activation is rather low, and thus, RT in this trial will be high. This conditioning view of temporal preparation readily explains RT performance and the presence of sequential effects in conventional foreperiod paradigms without reference to theoretical concepts such as expectancy. However, since this account assumes that the learned response corresponds to response-related (and thus, motor) activation, it is unclear whether this model can account for influences of temporal preparation on perceptual processing. Therefore, we will refrain from this view in this article, although the trace conditioning view provides a highly plausible account of how temporal preparation may affect nonperceptual processes.

3. This interval was introduced to keep overall trial duration constant regardless of whether the foreperiod of the present trial was short $(800 \mathrm{msec})$ or long $(2,400 \mathrm{msec})$. Otherwise, trial duration and foreperiod duration would be confounded, and one might argue that observed foreperiod effects might be better explained by differences in trial duration (cf. Bausenhart et al., 2007). For example, within a given amount of time, the targets would be presented more often in the short foreperiod condition than in the long foreperiod condition, and thus memory representations of the target stimuli might be especially strong, or participants might be more alert because they have to respond more often.

4. We thank Simon Grondin for suggesting this experiment.

(Manuscript received December 20, 2007; revision accepted for publication June 19,2008 .) 